\title{
Dental professionals' role in the fight against COVID-19: current evidence
}

\section{Lauren Crowder ${ }^{1}$}

\section{A commentary on}

\section{Checchi V, Bellini P, Bencivenni D, Consolo U.}

COVID-19 dentistry-related aspects: a literature overview. Int Dent J

2020; DOI: 10.1111/idj.12601.

\section{Practice points}

- As patients can be asymptomatic for COVID-19, all patients should be treated as potentially infectious.

- Dental professionals have means to reduce infection and spread in the dental setting through screening patients, use of correct personal protective equipment, aerosol limitation and disinfection.

- Teams must ensure they are aware of emerging and updating evidence as we learn more about the virus in order to ensure we play our part in helping to fight COVID-19.

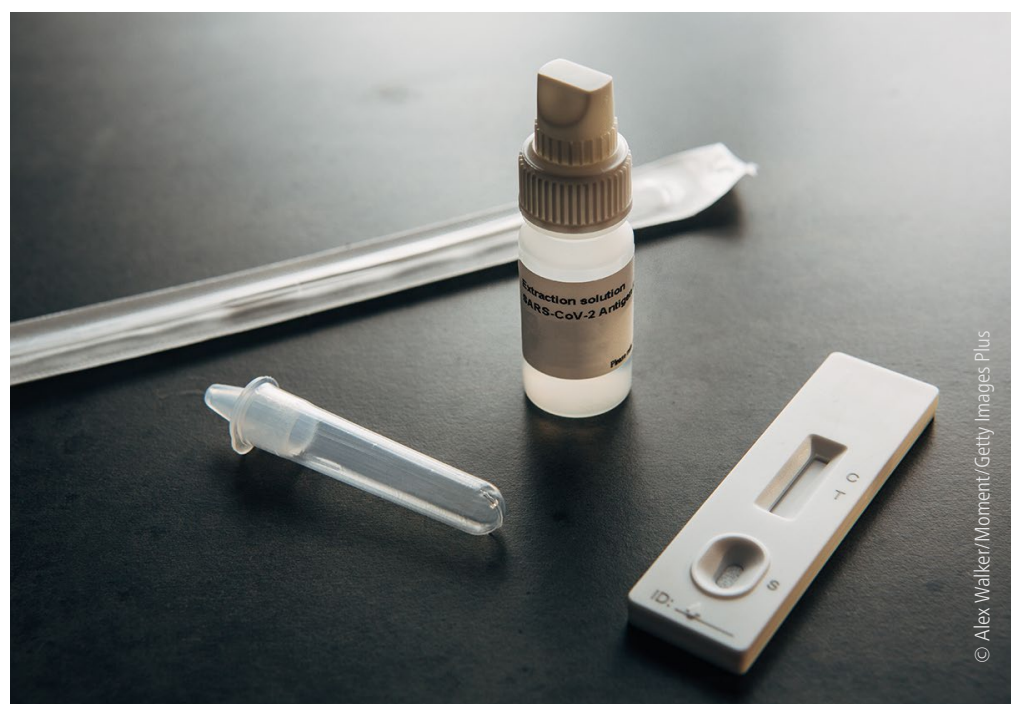

spread and potential lessons that they have learnt. There is no mention of the quality of the included studies, which could have a large bearing on the reliability and thus usefulness of the result. The authors do not state the number of articles yielded from the search. There is a specific database for COVID-19 - COVID-19 Open Research Dataset (CORD-19-2020) - which was not utilised. The screening of included article references does, however, help avoid loss of further potentially relevant studies.

A positive of the review was the clear structure of the results. The results were displayed in a discussion format under subheadings: transmission, protection mechanisms to avoid infection and those to avoid spread (both further subdivided), and disinfection. The introduction and each result section not only explained the practical points but also the indications for the use of such points.

The authors divided protective mechanisms to avoid infection into airway and eye protection. They discussed the evidence for airway protection and the levels of masks available, with clear thoughts on the filtration efficiency comparing both European and US standards and when they should be worn. They also reviewed masks with and without filters. Eye protection was considered essential as the ocular pathway is a known route of infection. Enveloping frames with shields covering as much of the face as possible are best. 
The mechanisms to prevent spread of COVID-19 were subdivided into medical history, environmental disinfection, antimicrobial agents, hand hygiene, minimally invasive procedures, use of rubber dam, high-speed saliva ejectors, antiretraction high-speed handpieces and dental environment sanitation. Patients with temperatures above $37.5^{\circ} \mathrm{C}$ should not be treated in a dental setting.

The results considered the use of triaging patients to limit the chances of COVID-19-positive patients entering the dental setting - in particular, the use of temperature measurements and close contact isolation. Environmental disinfection was broken down into the viability of viruses after time on differing materials. Using disinfectants at specific strengths can eliminate the virus on surfaces in one minute. The evidence for the use of mouthwash before treatment was minimal. The hand hygiene section explained the action of both soap and alcohol disinfection on the virus.

Minimising the creation of aerosols can be done through use of hand instruments, extraoral radiographs rather than intraoral, and use of rubber dam and high-speed saliva ejectors. The article noted the need for anti-retraction high-speed handpieces in order to reduce the drawing in and subsequent ejecting of contaminants, leading to cross infection.

Lastly, the review looked at sanitation and highlighted that no single device is specifically effective against COVID-19. Air purifiers can filter droplets smaller than 0.01-0.3 $\mu \mathrm{m}$ (virus particles are estimated to be $0.05-0.14 \mu \mathrm{m})$. Ozone, a natural gas, can oxidise viruses through free radicals. Ultraviolet radiation can be used to eliminate viruses by damaging DNA and RNA. Although, again, the quality or number of articles advocating for each of their use was overlooked.

No limitations of the review were mentioned until the conclusion, where it highlighted that the review, although up to date at the time, may have had some of its results superseded by evidence published post-literature search.

Despite the obvious limitations mentioned, the report is clear and succinct, giving professionals several definite and precise advice points, while underpinning the reasons why.

\section{Author affiliation}

${ }^{1}$ Paediatric Department, Glasgow Dental Hospital, Glasgow, UK. Correspondence to: Lauren Crowder

\section{References}

1. World Health Organisation. WHO Director-General's opening remarks at the media briefing on COVID-19 - 11 March 2020. 2020. Available at https://www.who.int/ director-general/speeches/detail/who-director-general-s-opening-remarks-at-themedia-briefing-on-covid-19---11-march-2020 (accessed May 2021).

2. Centres for Disease Control and Prevention. Ways COVID-19 Spreads. 2021. Available at https://www.cdc.gov/coronavirus/2019-ncov/about/transmission.html (accessed February 2021).

Evidence-Based Dentistry (2021) 22, 62-63.

https://doi.org/ 10.1038/s41432-021-0183-1 